CRÍTICA, Revista Hispanoamericana de Filosofia

Vol. XXVI, No. 78 (diciembre 1994): 73-95

\title{
TRANSCENDENTAL IDEALISM AND PHENOMENALISM
}

Marco Antonio Frangiotti

Universidade Federal de Santa Catarina

\section{Introduction}

Kant's transcendental idealism has been equated to Berkeley's idealism by many commentators. According to them, by denying the access to objects beyond the field of experience and by constraining our epistemological claims to possible objects, Kant would have just repeated Berkeley's fundamental principle that existing objects can only be those ones that are capable of being perceived. ${ }^{l}$ Thus put, Kant would have elaborated, in a Berkeleian style, a doctrine that the material and the mental constituents of the world are just appearances. ${ }^{2}$ Like Berkeley, then, Kant would have reduced the objective aspects of the world to mere ideas dependent upon the mind and thereby would have committed himself to phenomenalism. I intent to defend here that, although it is possible to point out several apparent similarities between Berkeley and Kant, their philosophies are quite different from each other and, therefore, transcendental idealism must be thought of as distinct from phenomenalism.

${ }^{1}$ Cf. Strawson, 1966, pp. 18 and 240.

${ }^{2}$ Cf. ibid., p. 22. 


\section{Apparent Similarities}

The viewpoint that transcendental idealism is a version of Berkeley's thought is by no means recent. It was vindicated by several philosophers contemporary to Kant. Garve and Feder, for example, commenting on the Critique of the Pure Reason in 1782, presented Kant as a radical idealist whose system "equally embraces spirit and matter" and "turns the world and ourselves into mere representations". ${ }^{3}$ Such a system is said to be based on the idea that "sensations" are "mere modifications of ourselves, whereupon also Berkeley primarily constructed his idealism". 4 More recently, Turbayne argued that Kant's thought is just a variation of Berkeley's, so that "Kant's many attempted refutations of dogmatic idealism fail before they begin". 5 Wilkerson, in turn, contends that Kant "is a Berkeleian", because "he wants to reduce objects to collections of perceptions". ${ }^{6}$ Finally, Strawson challenges transcendental idealists to distinguish their view from a phenomenalistic one, whereas Kantian bodies in space are viewed as mere perceptions and "apart from these perceptions bodies are nothing at all". 7

A non-detailed view on Berkeley and Kant can lead one to agree with Strawson and others. In fact, it is undoubtable that there are several affinities between them. Both Kant and Berkeley, for example, criticize those ones who advocate the absolute reality of space and time. As Berkeley states in the Principles, "it seems [...] evident that the various sensations or ideas imprinted on the sense $[\ldots]$

\footnotetext{
3 Garve \& Feder, p. 40.

4 Ibid., p. 41.

5 Turbayne, 1955, p. 225.

6 Wilkerson, 1976.

7 Strawson, 1966, p. 57.
} 
cannot exist otherwise than in a mind perceiving them". 8 In tune with this, Kant says that "there is nothing in space save what is represent in it [...], for space is itself nothing but representation, and whatever is in it must therefore be contained in the representation". ${ }^{9}$ Their reasons to discard the absolute notion of space and time are almost interchangeable. Berkeley points out that a notion like pure space requires the assumption that it "exists after the annihilation of all existing entities, including God". ${ }^{10}$ In this sense, we are led to believe that "there is something beside God which is eternal, uncreated, infinite, indivisible, immutable". ${ }^{11}$ Now, since this alternative points to an inconsistent notion of divine space playing the role of the primary condition of the existence of all beings (including God), the notion of pure space seems to be pernicious and absurd. ${ }^{12}$ As per Kant, absolute space and time, as "two eternal and infinite self-subsistent non-entities", must be "the necessary conditions of the existence of all things, and moreover must continue to exist, even although all [...] things are removed". That being the case, "they must also be the conditions of the existence of God". ${ }^{13}$ Once dependent upon nothing, all things are ipso facto "transformed into mere illusion". Hence, Kant also calls those notions "absurdities". 14

Kant and Berkeley are also in agreement with respect to the inadequacy of metaphysical realism, i.e., the doctrine that real objects lie outside the experiential field and that

8 Principles I, $\S 3$.

9 A 374a.

${ }^{10}$ Cf. De Motu p. 53.

11 Principles, § 117.

12 Cf. ibid.

13 B 71.

14 B 70. 
thereby installs an unbridgeable gap between material substances or things in themselves and ideas or empirical data. Philosophers who defend this view, Berkeley contends, are deluded to think they can "conceive bodies existing unthought of or without the mind; though at the same time they are apprehended by or exist in itself" ${ }^{15}$ Kant endorses this idea by saying that transcendental realists are "led to the childish endeavour of catching at bubbles, because appearances, which are mere representations, are taken for things in themselves". ${ }^{16}$ Nothing is more pernicious to philosophy than the defense of the idea of objects lying beyond our ken. "It is evident", Berkeley esteems, that "there can be no substratum of [...] (sensible) qualities [...] I deny therefore that there is any unthinking substratum of the objects of sense, and in that acceptation that there is any material substance". ${ }^{17} \mathrm{He}$ explains that by material substance he means "an unknown somewhat (if indeed it may be termed somewhat) which is quite stripped of all sensible qualities, and can neither be perceived by sense, nor apprehended by the mind". ${ }^{18}$ Since this notion can lead us to the conclusion that we know nothing real in the world, its acceptance has to be seen as "wild and extravagant". ${ }^{19}$ This talk is given a reformulation by Kant so many times in the Critique. Berkeley's 'material substance' is called 'thing in itself', which cannot be known because it is by definition independent of the senses and ipso facto non spatio-temporalized. ${ }^{20}$

15 Principles, § 23.

16 Prol., p. 292; cf. A 491.

17 Dialogues, p. 71.

18 Ibid., p. 92.

19 Ibid., p. 62.

20 Cf. B 45, 67, A 369, B 522 and passim. 
Once the idea of objects lying outside the sphere of experience is brought into play, both Kant and Berkeley argue that philosophy becomes inextricably doomed to be undermined by the skeptical assault. Kant, for example, states that it is by no means comprehensible "how we could arrive at a knowledge of their reality outside us, since we have to rely merely on the idea which is in us". ${ }^{21}$ There is no doubt that Berkeley anticipated such a view when he claims that, "so long as we attribute a real existence $[\ldots]$ to things distinct from their being perceived, it is not only impossible for us to know with evidence the nature of any real unthinking being, but even that it exists". ${ }^{22}$ If ideas "are looked on as notes [...] referred to things or archetypes existing without the mind, then are we involved all in skepticism", for it is "out of our reach" to say for sure that there are such things. ${ }^{23}$

The points of contact between Kant and Berkeley do not stop here. It is not difficult to notice a sintony between them with respect to the solution for these complications. Kant affirms that the only "refuge" the skeptic still leaves open to us is "the ideality of all appearances". ${ }^{24}$ In fact, "all appearances are not in themselves things; they are nothing but representations, and cannot exist outside our mind". ${ }^{25}$ Taking this into account, we must see "our knowledge of the existence of things" as reaching "only so far as perception". ${ }^{26}$ Berkeley, in turn, defends a similar thesis. "Their esse", he says, "is percipi", and it is by no means possible that "they should have any existence out

\footnotetext{
21 A 378.

22 Principles, § 87; cf. ibid., § 88.

23 Principles I, § 87.

24 A 378.

25 A 492.

26 A 226.
} 
of the minds or thinking things which perceive them". ${ }^{27}$ Sensible things are "immediately perceived; and things immediately perceived are ideas; and ideas cannot exist without the mind; their existence therefore consists in being perceived". ${ }^{28}$

Consequently, both Kant and Berkeley affirm that there is no need to infer the reality of external objects. Since they are just those that we encounter in our experience, they can be known immediately. This can be confirmed by recalling Berkeley's words that "I am as certain as of my own being, that there are bodies or corporeal substances (meaning the things I perceive by my senses)". ${ }^{29}$ Such a statement seems to echo in Kant's assertion that "external things exist as well as I myself, and both, indeed, upon the immediate witness of my self-consciousness". ${ }^{30}$ As a matter of fact, "the inference from a given effect to a determinate cause is always uncertain, since the effect may be due to more than one cause". ${ }^{31}$ If this were so, we could never be completely sure about the real causes of our picture of the external world, so that our doctrine would be compromised by the possibility that something else intervened to produce the available effects, as it is the case in some skeptical hypothesis, viz., the evil demon, the mad scientist, etc.

To those topics it can be added that Berkeley as well as Kant distinguish reality from illusion invoking a similar argument. Berkeley claims that ideas perceived by the sense "have [...] a steadiness, order, and coherence, and are not excited at random, as those which are the effects of

27 Principles, $\S 3$.

28 Dialogues, p. 64.

29 Ibid., p. 71.

30 A 371.

31 A 368. 
human wills often are, but in a regular train or series". ${ }^{32}$ Kant, in turn, is by no means far from saying the same thing. "The difference between truth and dreams", he explains, "is $[\ldots]$ decided by $[\ldots]$ the connection of $[\ldots]$ representations according to the rules that determine the combination of them in the concept of an object". ${ }^{33}$ In the same way, it is conclusive that both Kant and Berkeley argued that the distinction at issue is not based on an alleged relation of ideas to a super-sensible world, but on the coherence and the lawlike character of the empirical items. ${ }^{34}$

\section{Confronts}

These points being noted, it is comprehensible why some commentators put Kant's and Berkeley's doctrines on the same footing. Kant, however, tried to discourage this view several times. His strongest attempt to do so can be found in the Appendix of the Prolegomena. There he says that, while Berkeley regarded space (and time) as merely empirical, he himself esteems them to be a priori.

From this it follows: that as truth rest on universal and necessary laws as its criteria, experience with Berkeley can have no criteria of truth because nothing was laid (by him) a priori at the ground of appearances in it, from which it then followed that there was nothing but illusion; whereas for us space and time (in conjunction with the pure concepts of the understanding) prescribed their law a priori to all possible experience, and this yields at the same time the sure criterion for distinguishing truth in it from illusion. ${ }^{35}$

32 Ibid., $§ 30$.

33 Prol., p. 290.

34 Cf. A 493; Principles, § 35.

35 Prol., p. 374. 
Now, Kant is not in error to distinguish himself from Berkeley by pointing out that space and time are a priori. Berkeley deals with space or "outerness", for example, as "only suggested to our thoughts by certain visible ideas and sensations attending vision" and eo ipso "taught us by experience". ${ }^{36}$ However, it seems rather obscure to figure out why this is a key point to distinguish those two philosophers and to detect which one is able to effectively separate truth and illusion. If they both have the same criterion to carry out this distinction, we are led to suppose that Kant is here implying that such a criterion is irremediably compromised once one considers space and time as empirical. However, this is not exactly what is acknowledged by Kant when he states the origin of illusion:

if I venture to go beyond all possible experience with my concepts of space and time $[\ldots]$ then a grave error may arise due to illusion in which I proclaim to be universally valid what is merely a subjective condition of the intuition of things [...] I would refer this condition to things in themselves and not limit it to the conditions of experience. ${ }^{37}$

If illusion arises, according to this passage, when space and time are taken as properties of things in themselves, Kant's attempt to overshadow Berkeley somewhat fades in front of us, for Berkeley cannot be blamed for applying space and time to the super-sensible world. Space and time are properties of perceptible objects (Kantian appearances) and not of material substances (Kantian things in themselves).

Now, is Kant really correct when he says that Berkeley, by not figuring space and time as a priori, ends up de-

36 Principles, § 43.

37 Prol., pp. 291-292. 
grading bodies to mere "illusions", 38 or "phantasms"? 39 Is it the case that Berkeley did not acknowledge the difference between, say, my packet of cigarettes over there and the image of a centaur up here in my head? Apparently, he did. Some of our ideas are indeed said to come from without. ${ }^{40}$ Kant seems, then, to beg the question against Berkeley. Of course Berkeley acknowledges that there is a difference between empirical objects and mental states; no one could possibly take seriously a doctrine that equated them without further ado.

Despite all these Kant's obscurities, I hold it is possible to reevaluate his account and, by means of this, to dig a gap between him and Berkeley. If I consider my packet of cigarettes in relation to the image of a centaur, the obvious difference between them is that, while the latter is just an item in the procession of my mental states, the former fills space and bears a specific location in space (and time). On the one hand, the image of a centaur is only temporally ordered, i.e., it is an item that precedes and succeeds other items in the sequence of my mental states, and eo ipso it yields no shape, no spatial position whatsoever. On the other hand, my packet of cigarettes is not only temporally but also spatially ordered, i.e., it bears some properties which allow me to characterize it as outside and alongside other objects and to distinguish it from my mental states.

Well, would Berkeley say otherwise? No, he would not. However, his account is defective and encourages a view that empirical objects cannot be properly distinguished from mental states. Why is this so? Because, according to Berkeley, space is empirical: we learn about space as we learn about colours; for example, by observing features

38 Cf. B 71; Prol., p. 473.

39 Prol., p. 293.

${ }^{40}$ Cf. Dialogues, p. 82. 
of our ideas or mental states and their relations. Spatial order, then, turns out to be derived from temporal order, i.e., the order whereby ideas are given to the senses. Now, this suggests that the spatial features of the external object, i.e., features that are supposed to characterize this object as something really distinct from my mental states, are paradoxically derived, at the end of the day, from my mental states.

Thus put, Berkeley could only account for the temporal succession of the items that are given to the senses and from this order infer the spatial one. Hence, he ended up treating all the data of sensibility in the same way. Empirical (spatial) objects as well as mental states can, in view of this, be ultimately ordered in a temporal manner. These two different classes of sensorial items are thereby acknowledged to bear identical status. As a consequence, it is reasonable to say that Berkeley fails to explain how external, spatial objects are indeed independent of mental states. In other words, he fails to separate mental states, e.g., the image of a centaur, from the external items of the world, e.g. my packet of cigarettes. A fortiori, he is incapable of sustaining any legitimate distinction between illusion and objective reality.

Does Kant avoid this problem? I believe so. According to Kant, space and time precede the objects given to sensibility. They are not learned through the observation of our ideas and their relations. They rather constitute the whole sphere of experience. Within such a picture, spatial order does not depend upon the order in which objects are given to the senses. In that way, spatial features of the objects can be properly accounted for as distinct from temporal order. Now, since my mental states are only temporally ordered it is reasonable to say that Kant has at his disposal the means to characterize spatial features of the objects as independent of my mental states. 
Such a line of reasoning led Kant to conceive sensibility as exhibiting a twofold character, which allows us to order the sensorial data in two different ways, namely, spatially and temporally. Our sensibility is in fact composed by an inner and an outer sense. ${ }^{4 l}$ On the one hand, sensibility gives me mental states that encompass the whole sphere of my mental history, no matter if they represent empirical objects or not. I can say that all I am experiencing right now, say, the sight of my computer in front of me, the movements of my fingers typing English words in the keyboard, the image of the house I was born in (not so long ago), the image of a centaur, etc., all these thoughts are mental states that succeed one another in a constant flux up here in my head. This character of my sensibility is called by Kant "inner sense". ${ }^{42}$ If we had only an inner sense, or if our sensibility were just internal, all we would have at our disposal would be fleeting items that constituted a temporal order. In that event, nothing could count as spatially ordered. Why is this so? Well, a temporal order is just an order of succession, precedence and simultaneity, while a spatial order is an order whereby objects are represented in different places, and, above all, as distinct from my thoughts or, as Kant says, "in a different manner than myself". ${ }^{43}$ Kant calls eo ipso time as the form of the inner sense and space as the form of the outer sense. ${ }^{44}$ Through the inner sense alone it is not possible to represent objects

41 For purposes different than mine, Forster raises a slightly similar point (cf. Forster, 1985, p. 297). However, he seems to overlook the fact that the doctrine of inner and outer senses is based upon the apriority thesis for space and time. Hence, he wrongly says that this conception of a twofold sensibility is the very heart of disagreement between Kant and Berkeley.

42 Cf. B 37, passim.

43 Ak. XVIII, p. 309.

44 Cf. B 42 and B 49, respectively. 
as distinct not only from one another but also, and specially, from my thoughts, because inner sense orders items temporally and not spatially. Only the outer sense alone can perform the task of representing the objects spatially, i.e., as outside me. Through the outer sense we can say that spatial features of external objects are ordered in a different way than my mental states. ${ }^{45}$

An objection could be raised here. Even if one complied with Kant's criticism that spatial order is not subjected to temporal order, one could still reply that, for both Kant and Berkeley, space is somehow dependent upon sensibility. Although Berkeley argues that space is learned from experience and Kant argues that it is constitutive of it, both believe space is a feature of sensibility and, for this reason, an item dependent upon us. Thus put, it seems that Kant is also defending that spatial features of objects are somehow subject-dependent.

The answer to it is as follows. By not acknowledging the a priori elements of our experience, Berkeley could not establish in what sense this subject-dependence is to be understood. Thus, he can be said to conflate the two spheres of discourse about experience, namely, the empirical and the reflexive levels (this latter called by Kant transcendental reflection). ${ }^{46}$ On the empirical level, we just describe what we experience, say this book I am holding, the chair I am sitting on, that chessboard, etc. On the reflexive level, in turn, we examine experience in terms of the conditions whereby alone it takes place. Kant disagrees with Berkeley on the two levels. In a reflexive consideration, when we seek to determine the conditions of experience, space and

45 From this it follows that, according to Berkeley, we have only an inner sense, for spatial order (provided by the outer sense) is ultimately reduced to temporal order (inner sense).

46 Cf. B 317. 
time must be thought of as (logically) preceding it and not, as Berkeley thought, derived from it. On an empirical level, the external object is considered subject-independent and not just a collection of subject-dependent items, i.e., ideas.

A Berkeleian philosopher could ask what it all means. A Kantian answer to it could be this. When we reflect upon experience, i.e., when we consider experience on a transcendental level, we acknowledge the role played by the subject in the constitution of the objects of experience. From this point of view alone we are entitled to speak of those objects as transcendentally ideal, i.e., subject-dependent. This does not mean that those objects are considered subjectdependent on the empirical level. What is given to the senses, this chair, my computer, the printer, etc., are said to be empirically real objects, i.e., objects independent of the mind. They constitute the publicly perceptible, spatiotemporally ordered empirical world. ${ }^{47}$ By not being able to determine what aspects of the object are a priori, Berkeley could not account for the constitutive elements of experience that are collaborated by the subject and that are thereby dependent upon it. At the same time, he could not account for those elements of experience which are not dependent upon the subject. In the wake of this, he could not distinguish those a priori features of the object from the empirical ones. He then conflated subject-dependent features with subject-independent ones. Consequently, he failed to characterize the empirical items of experience as subject-independent after all.

In Kant's terminology, Berkeley fails to distinguish the form whereby we represent empirical objects and that is subjective, from the empirical aspects that are not contributed by the subject but are encountered by it. Tran-

${ }^{47}$ Cf. Allison, 1983, p. 7. 
scendental idealism then concerns only the former and not the latter. Kant is quite clear about that in a letter to Beck:

Eberhard's and Garve's opinion that Berkeley's idealism is the same as that of the critical philosophy [...] does not deserve the slightest attention. For I speak of ideality in reference to the form of representations, but they interpret this to mean ideality with respect to the matter, that is, the ideality of the object and its very existence. ${ }^{48}$

From Berkeley's doctrine, in fact,

an even wider skepticism has been advanced, viz., that we cannot know at all whether our representations correspond to anything else (as object) which is as much as to say: whether a representation is a representation (stands for anything). For "representation" means a determination in us that we relate to something else ${ }^{49}$

In other words, it is not possible for Berkeley to distinguish mere subjective aspects of objects from the actual experience of them as outside us. For these reasons, Kant admits in the Prolegomena that his idealism could also be called "formal" or "critical", in order to "distinguish it from the dogmatic idealism of Berkeley and from the skeptical idealism of Descartes". 50

At this juncture, Kant accuses Berkeley of being a realist on the reflexive level or, more precisely, a transcendental realist. Apparently, it seems odd to put Berkeley on the same footing as other transcendental or metaphysical realists, like Descartes, or Leibniz, for example. Descartes could be one of those who are described by Berkeley as arguing for archetypes behind objects. Descartes' dualism,

48 Letter to J.S. Beck of 4th December 1972, in Zweig, 1967, p. 198.

49 Ibid.

50 Prol., p. 375; cf. B 519. 
as a matter of fact, resides in the supposition that the real world is not accessible to us because all that we have at our disposal are representations of objects. Descartes installs, thus, a gap between our view of the world and the way the world really is. In the wake of it, he fills in this gap by appealing to God's benevolence. Now, since Berkeley dispatches such a double world view, it seems that Kant is once more inaccurate in describing Berkeley.

As I see it, however, it is possible to make sense of Kant's remarks on Berkeley's position. According to Berkeley, real objects, although accessible to us, are conceived as independent of the subjective conditions of experience (space and time) in the same manner as the real objects characterized by Descartes. They are given to us already made or constituted without regard to the subject which, in turn endeavours to conceptualize them. They are given to us, one may say, as they are in themselves -i.e., as they are apart from the subject's intervention in generating them. ${ }^{51}$

Thus, although Descartes believed that real objects were not accessible and that Berkeley believed otherwise, they both made the same kind of mistake: they deprived the real object of the subjective elements whereby alone such an object is constituted. Taking this point into account, it is understandable why Kant contends, as observed above, that Berkeley conceives space and time in connection with things in themselves.

At the same time, according to Kant, Berkeley can also be classed as an empirical idealist. On the empirical level, Berkeleian objects are ultimately derived from us, i.e., they are ideas entertained by the subject. ${ }^{52}$ There is no way of counting empirical data as coming from without. In

51 I am here in agreement with Allison (cf. Allison, 1983, pp. 16-19).

52 Cf. Dialogues, p. 77. 
this manner, empirical as well as subjective aspects of the object are totally subject-dependent at the end of the day. This is how I interpret Kant's description of the empirical idealist fallacy. He states that, by supposing that objects, if they are to be external, "must have an existence by themselves, and independently of the senses", the empirical idealist "finds that, judged from this point of view, all our sensuous representations are inadequate to establish their reality". ${ }^{53}$ Empirical idealism entails illusion because it assumes that space and time are empirical and at the same time it maintains that they are ideal, i.e., subjectdependent. Berkeley's dualism is then fragile, for it reduces empirical objects to mere subject-dependent items, or to mere mental states. Whatever is experienced turns out to be just a modification of the mind, i.e., a mental, internal episode in the history of a subject (e.g., the image of my mum's face, Macbeth's dagger, etc.). The tree I conceive by closing my eyes and the tree I experience and take it to be outside me are said to hold the same epistemological status as any other item dependent upon the mind.

\section{Phenomenalism and Unperceived Objects}

What has been said so far provides us the means to determine whether or not Kant was a phenomenalist. In order to show why this is so, let me first of all take account of what phenomenalism is. We may say that a phenomenalist argues that the external object is constructed out of sense data. Whatever features the object may have, it has to be possible to perceive them. In this way, object language statements have to be translatable into sense data statements in order to acquire meaning. ${ }^{54}$ An instructive way

53 A 370.

54 This definition is borrowed from Bennett (cf. Bennett, 1971, pp. 136-137). 
of making this point clearer is to inquire what a phenomenalist has to say about unperceived objects. According to him, statements about unperceived objects would be given meaning just as long as they are reducible to statements about sensorially perceived objects. For example, my supervisor's office, and all the objects in it, although they are not being perceived by me who am over here right now in my study room before my computer, are accounted for as objects only insofar as I can speak of them as though I were there. Thus, I can say that, "if I were there, I would be perceiving them as empirical objects". What there is consists of all that can be grasped through the senses, so that the objects are made entirely by sense data.

We do not need to think twice in order to characterize Berkeley as a phenomenalist. As I have shown above, his central thesis that "esse is percipi" means just that an object can be classed as such save insofar as it is perceived. Its features are only accounted for if they are in principle capable of being perceived, i.e., if they are made thoroughly by sense data. This does not mean that the object has to be perceived by me in particular; it means that it has to be perceived by any mind. The Australian tree exists because it is possible that there be other minds capable of perceiving it, even if I never existed. ${ }^{55}$ It is easy to infer from this that, as per Berkeley, empirical objects are reduced to mental states, either mine or someone else's. Empirical objects always require an entertainer. Once the idea of a sentient being, whoever he might be, is taken out of the picture, the idea of empirical objects vanishes.

If the phenomenalist defines the external object as a collection of sense data, we are entitled to say that Kant is not a phenomenalist. This is so because, according to him, the object is not constructed out of sense data, i.e., it does not

55 Cf. Principles, $\S 3$. 
display only empirical aspects, and a fortiori is not just a mental state. The object is said to be, on a transcendental or reflexive consideration, constructed through certain a priori constitutive elements lying in the subject. On the empirical level, the object is considered a subject-independent item in the external world and not just a mental state. If one insists in labelling Kant as a phenomenalist, then, one has to change the meaning of the term, or to realize that Kant's notion of phenomenon or of empirical object is pretty much different from Berkeley's or any other phenomenalist.

Now, what is the philosophical profit of this difference? The answer is that Berkeley deals with the criterion of truth, i.e., the law-governed character of the external objects, in a very mistaken way. By not having at his disposal a priori elements that constitute empirical objects, Berkeley could not abstract from actual experience and seek out its constitutive rules. He could only say that the laws of regularities amongst empirical objects come with them to our minds. Those laws are encountered and learnt by us in the course of our experience. But since for Berkeley the object is always an item being entertained by a sentient being, and since the laws of regularity pertain the object, then those laws cannot be sustained once the actual presence of an entertainer is taken out of our account.

In this way, when Berkeley is faced, for example with the supposition of annihilation of the whole humankind, he has no option but to appeal to a divine entertainer in order to preserve his picture of the external world. He could only argue that objects continue existing because they are perceived or entertained "ultimately by the omnipresent eternal mind of God, which imposes to our view rules that order things and as such are called laws of nature" ${ }^{56}$ Hence, no matter who the entertainer is, whether human or

56 Dialogues, pp. 64-65; cf. Principles, § 6. 
divine, the empirical object is nothing but a mental state, a psychological moment in the history of a sentient being. This is, however, much too high a price to pay. Berkeley ends up compromising his own phenomenalistic account, for he takes us beyond the limits of possible experience. God and the archetypes in the divine intellect cannot be met up with by empirical means, so that he drives the notion of empirical object and its laws to a no-man's land. By not being able, says Kant, to determine "anything that the understanding grasped in accordance with a priori principles", Berkeley had no option but to "look for [...] divine ideas". ${ }^{57}$ Now, if it is true that for Berkeley the laws of regularity pertain the object, there is no plausible way, in this no-man's land, of characterizing them as a suitable criterion to separate truth from illusion. This criterion, together with the object, is thrown out of the borders of our experiential field and is reduced to ashes.

Keeping this in mind, I suggest a minor correction in Kant's commentaries on Berkeley. It is true that this latter does have a criterion of truth. However, this criterion is unworkable in a doctrine that deems space and time as empirical. In this way, although it is inaccurate to say that Berkeley has "no criteria of truth", 58 it is rather plausible to speak of this criterion as useless in Berkeley's picture of the external world. Berkeley, at the end of the day, lacks a mechanism to dissociate subject-dependent from subject-independent items of experience. Berkeley cannot provide the means whereby we may justifiably determine how objects are like in the empirical world.

In Kant's view, however, the law-governed character of the external world is treated in a very different way. The apriority thesis of space and time allows him to step out of

$57 A k$. XXIII, p. 58.

58 Prol., A 375. 
actual experience and to establish the a priori rules to be obeyed by the empirical world that are called the principles of the pure understanding. ${ }^{59}$ Such a structure, in turn, must be acknowledged as constitutive of experience and not, pace Berkeley, simply discovered in it. Accordingly, while phenomenalism reduces any objectual statement to sense data statements, Kant's approach seems to run the other way round. By means of sense data statements alone it is not at all possible to decide the truth value of non-sense data statements, for sense data statements must conform themselves to a previously settled structure erected by a priori rules. ${ }^{60}$ Through a priori subjective conditions, then, a certain class of non-empirical statements which legislate over the empirical world are established without any regard to empirical statements. As a matter of fact, the former are said to provide, at the end of the day, the credentials for the determination of the truth value of the latter. ${ }^{61}$

I do not deny that Kant does seem close to Berkeley, i.e., to a phenomenalistic account when he talks about unperceived objects, particularly when he accounts for objects prior to my existence. He says that those objects can be thought of by means of an empirical regress which starts from the present moment I am experiencing them. ${ }^{62}$ This may sound phenomenalism because Kant might be taken to be proposing that our conception of unperceived objects is subjected to our conception of perceived or sensorially given objects. However, to say that a past or a future state of affairs can be reached by taking into consideration the present experiential moment is to say that it is possible to establish a lawful chain between past or future and present

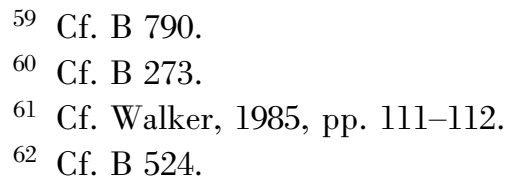


states of affairs. ${ }^{63}$ This provides us the means to build up a conception of a law-governed external world without the presence of a human subject and, at the same time, without the appeal to God or to other super-sensible device. A law-governed world without sentient beings, without entertainers, is made, then, comprehensible within the scope of our experiential field and without an unpalatable recourse to a world beyond our ken that is kept existing by the almighty intervention of Providence.

\section{REFERENCES}

Allison, H.E., 1983, Kant's Transcendental Idealism (New Haven and London: Yale University Press).

Bennett, J., 1966, Kant's Analytic (Cambridge: Cambridge University Press).

Berkeley, G., 1979, A Treatise Concerning the Principles of Human Knowledge (Indianapolis: Hackett) (abbreviated Principles).

_ 1982, Three Dialogues Between Hylas and Philonous (Indianapolis: Hackett) (abbreviated Dialogues).

Forster, E., 1985, "Kant's Refutation of Idealism," in A.J. Holland, Philosophy, Its History and Historiography (Dordrecht: D. Reidel), pp. 287-303.

Garve \& Feder in Göttinsichen Gelehrten Anzeigen, 19, January 1787, pp. 40-48.

Hume, D., 1978, A Treatise of Human Nature (Oxford: Clarendon) (abbreviated T).

Kant, I., 1990, Critique of Pure Reason (London: Macmillan) (translated by N.K. Smith and abbreviated A for the first edition and $\mathrm{B}$ for the second edition).

, 1902, Kant's Gesammelte Schriften (Berlin: Ed. Preussischen Akademie der Wissenschaften zu Berlin), 29 vols. (abbreviated $A k$.).

${ }^{63}$ Cf. Allison, 1983, p. 32. 
—_, 1977, Prolegomena (Indianapolis: Hackett) (translated by Sir James Ellington; abbreviated Prol.).

Strawson, P., 1966, The Bounds of Sense (London: Methuen). Walker, R.C.S., 1985, "Idealism: Kant and Berkeley" in J. Foster \& H. Robinson, (eds.), Essays on Berkeley (Oxford: Oxford University Press), pp. 109-129.

Wilkerson, T.E., 1976, Kant's Critique of Pure Reason: A Commentary for Students (Oxford: Oxford University Press). Zweig, A., ed., 1967, Kant's Philosophical Correspondence (Chicago: University of Chicago Press).

Recibido: 23 de enero de 1994 


\section{RESUMEN}

El idealismo trascendental de Kant a menudo es considerado una forma de fenomenalismo. De esta forma, algunos comentadores de Kant han equiparado su doctrina con la de Berkeley. Los defensores de este punto de vista han argumentado en forma general que, limitando el campo del conocimiento a objetos asequibles a los sentidos, Kant habría restablecido la principal fuerza propulsora del idealismo de Berkeley y reducido los elementos del mundo externo a simples representaciones o ideas. Aunque algunos de los pasajes de la Crítica de la razón pura apoyan este punto de vista, creo que el intento de clasificar a Kant como berkeleyano es equivocado. Por tanto, mi propósito en este artículo es demostrar en qué apectos sus filosofías pueden distinguirse una de la otra. Para hacerlo, establezco una línea de pensamiento según la cual Kant puede evitar ser acusado de fenomenalista.

[Traducción: Claudia Chávez] 